\title{
Public policies and selective visual attention: the effectiveness of awareness messages among young people about the consumption of alcoholic beverages in Brazil
}

\author{
Renê de Oliveira Joaquim dos Santos ${ }^{1}$, Jorge Henrique Caldeira de Oliveira ${ }^{1}$, \\ Janaina de Moura Engracia Giraldi ${ }^{1 *}$ and Adriano Rogério Bruno Tech ${ }^{2}$
}

${ }^{*}$ Correspondence:

jgiraldi@usp.br

${ }^{1}$ University of São Paulo

(USP), Av. Bandeirantes 3900,

Monte Alegre, Ribeirão Prêto,

SP CEP 14040-905, Brazil

Full list of author information

is available at the end of the

article

\begin{abstract}
The aim of this study was to determine the effectiveness of mandatory conscious consumption warnings on alcohol advertisements in Brazil among young adults. Through Neuromarketing technique using Eye Tracking equipment, the visual attention behavior of young consumers was verified in laboratory, when they were exposed to beer commercials. The results demonstrated that the effectiveness of these warnings is very low and that this type of public health policies is not having the desired effects. These results emphasize the need to better understand how to attract the visual attention of consumers to these warning messages, clearly demonstrating that the current formats do not play their role of prevention and awareness.
\end{abstract}

Keywords: Conscious consumption, Visual attention, Public policies

\section{Background}

Since the 1990s, Brazil is among the five largest brewers in the world, with high per capita consumption and wide consumption among young people, representing almost $70 \%$ of the national beer consumption (Rosa et al. 2006). The excessive alcohol consumption is associated with more than sixty types of diseases, directly or indirectly resulting from the uncontrolled alcohol intake and its continued excessive consumption. Diseases such as cirrhosis and cancer, mental disorders and aggressive behavior, and often these consequences go beyond the individuals themselves and cause damage to users' families (Albuquerque et al. 2007; Boffetta and Hashibe 2006; D'Andrea et al. 2013; Eloah et al. 2013; Pöschl and Seitz 2004).

In addition, there have been an increasing number of new customers in the age group of 12-18 years caused by family encouragement, positive associations made in the media or under the influence of friends encouraging consumption initiation and as a distorted form of reputation search among peers and closer interpersonal bonding. To control all these social and public health problems, measures and public policies have been

\section{Springer}

(c) 2015 de Oliveira Joaquim dos Santos et al. This article is distributed under the terms of the Creative Commons Attribution 4.0 International License (http://creativecommons.org/licenses/by/4.0/), which permits unrestricted use, distribution, and reproduction in any medium, provided you give appropriate credit to the original author(s) and the source, provide a link to the Creative Commons license, and indicate if changes were made. 
developed in the world and in Brazil to prevent excessive and irresponsible alcohol consumption (Duailibi and Laranjeira 2007; Visser et al. 2013).

One of these practices is the implementation of a Brazilian law prohibiting any alcohol concentration in the blood of drivers. Law 11.705, the "Dry law" of June 20, 2008, penalizes drivers caught driving under influence of alcohol (Malta et al. 2014). The penalty may consist of an administrative offense or even a criminal case, depending on the alcohol concentration. Two years after the implementation of the law, deaths caused by traffic accidents reduced by $6.2 \%$ across the country, ranging in federal states proportionally to the intensity of supervision (Ministério da Saúde 2010).

However, beverage industries use a great tool to increase the sales of their products, including beer advertisement. This is a powerful marketing tool and is part of the activities of creation and delivery of value to the customer. The marketing communication, including the use of new and more efficient technologies, plays the role of seeking, informing, persuading and reminding consumers, directly or indirectly, on the products and brands marketed by companies (Caswell 2004; Caswell and Maxwell 2005).

The Americas Beverage Company (AmBev), the largest Brazilian brewing company responsible for producing some of the major beer brands (such as Brahma, Antarctica and Skol), was the fourth company to invest more in advertising in Brazil in 2011. The Petrópolis Brewery (producer of Itaipava and Crystal brands) was the sixth more investing company. Their spending patterns aimed at encouraging consumption reproduce every year. The sector is always among the top investors in advertisement in Brazil.

In a movement to improve public health in Brazil, Law 9.294 was released in 1996. By means of visual warning communication, according to this law, companies must support the prevention of problems caused by alcohol and other harmful products, requiring a written warning against abuse. From that moment, all alcohol advertisements, smoking, drugs, therapies and others would contain phrases established by the Ministry of Health with warnings about the dangers of consuming the products. In the case of alcohol, phrases are: "don't drink and drive", "drink responsibly" and "product intended for adults" (Falcão and Rangel-S 2010).

Despite the importance of this issue to public health, there are no studies on the effectiveness of warning communications and if the target audience was really appropriately exposed to warning messages. That is, it is not known whether the proposed goals of reading warning messages are met. The reading would be the first step for the law to reach the proposed goals. One of the best ways to answer this question is to use the Eye Tracking technology. Eye-trackers are systems that estimate the gaze direction of an individual, that is, this technology enables checking where the individual is looking at. This enables identified which parts of the stimulus attracted the consumer's attention. Therefore, the eye-tracking is one of the most suitable techniques to understand how advertising incentives and warning messages are affecting consumer behavior, especially regarding the visual attention of these stimuli (Weigle and Banks 2008).

Modern eye-tracking technology, where devices have high precision in tracking the human eye under specific stimuli, is used today as one of the main tools in Neuromarketing and Biofeedback studies, in which neural and physiological responses are analyzed in a scientific manner with equipment typically used in medicine and related areas (Oliveira et al. 2014). 
Eye-tracking provides different methods to understand consumer behavior and evaluate packaging design, promotions, product placement and store planning and enables testing the effectiveness of print ads, television commercials, sports marketing and others (Fiszman et al. 2013). Another example is the use of this technique to analyze the website designer, the correct distribution of the website content to improve the navigation of users and make it more attractive and interactive (Buscher et al. 2010).

According to Velásquez (2013), eye movement can be divided into two categories; fixation movement, which is characterized as when the observer kept the gaze fixed at the stimulation point and the saccade movement, which represents the movement performed from one fixation to another. In this context, Nielsen and Pernice (2009) define fixation as the moment when the eyes are still on an object and one can see it in detail, while saccade corresponds to the rapid eye movements between two fixations.

Each neuromarketing technique studies different responses. Positron emission tomography (PET), Magnetoencephalography (MEG), functional Magnetic Resonance Imaging (fMRI), Electroencephalography (EEG), Galvanic Skin Response (GSR) and of course eye-tracking are among the main neuromarketing equipment. PET, MEG and EEG techniques are linked to brain anatomy images (Fugate 2007), while GSR identifies emotions based on the measurement of the electrical conductivity in the palms of hands and feet in the event of an imperceptible sweat (Montagu and Coles 1966; Oliveira et al. 2014).

One of the great benefits of neuromarketing techniques is to provide tools to investigate intentions, behavior and reactions of consumers. By simply conducting an interview with the consumer after a stimulus, he or she is often not willing to reveal his emotional reasons and preferences and decisions or what really caught his attention (Fugate 2007), or possibly does not remember or was not aware of what really attracted his attention. Using Eye Tracking, these barriers are overcome, allowing us to understand exactly what happened or at least to have a more precise idea of behaviors and reactions.

Social problems caused by excessive alcohol consumption has been a serious public health problem in many countries and in Brazil, bringing serious consequences for society in various aspects such as violence, diseases, accidents, increases in public spending and others (Almeida et al. 2013; Ferreira et al. 2011; Malta et al. 2014). Given the above, one may ask whether Law 9.294/96 is really useful as a measure to warn about excessive alcohol consumption. This study aims to understand the effectiveness of prevention and awareness messages to alcohol consumption in beer commercials by visual attention identification.

Therefore, the main aim of this research was to verify at laboratory using high-precision equipment, the immediate effectiveness of warning messages regarding excessive alcohol consumption in beer advertisements. These warning messages are critical for changes of unsustainable and irresponsible behavior regarding excessive alcohol consumption. Without this step, many public prevention policies do not go to a next step of results, which would basically be the effective behavior change.

Thus, two secondary objectives that supported the main objective were elaborated:

(A) To measure the viewing attention of young adults for warning visual stimuli in beer advertisements in an attempt to understand the visual behavior of individuals exposed to stimuli. To achieve this goal, two important visual attention 
data will be processed: duration of each fixation on areas of interest (AOIs) - the advertising regions linked to the brand, and total duration in all AOIs.

(B) To understand the level of memory and awareness of individuals that had just viewed images with warning messages. To achieve this goal, questionnaires were applied to understand the effectiveness of warning messages in the short-term memory of individuals exposed to stimuli.

\section{Methods}

This research used the Eye Tracking Tobii X1L equipment with data capture at $30 \mathrm{HZ}$. This is high-precision equipment with dual-camera system for the tracking of both eyes and automatic light and dark selection for tracking pupil. The tracking recovery time after the blink of an eye is $10 \mathrm{~ms}$ (Tobii 2014).

The experiment was conducted at laboratory installed on the facilities of a Public Brazilian University to collect data from young students. In the laboratory, participants were submitted to stimuli, i.e., they observed four advertising images taken from the pages of the social networks of Crystal and Skol beers.

These two brands were chosen because they are products at the extreme ends of the Market share, Skol is the market leader and Crystal is among the brands with much smaller Market share. Two advertising images were selected from each brand. The four images were intermittently displayed in a sequence of $28 \mathrm{~s}$ of total time, $7 \mathrm{~s}$ for each image.

Skol beer images showed the following warning: "don't drink and drive". Crystal beer images showed the following warning: "drink responsibly". Both warning messages are in accordance with Brazilian Law 9294 of July 15, 1996, in which advertisements should contain warning messages to prevent the excessive alcohol consumption. All images available on the social networks of companies had the same standard; therefore, the images selected had the same standard of what is recurrently used in advertisements. The criteria used to select the images were (A) to have the same standard of warns as other images; (B) to have some type of written message, not only visual.

The Tobii3.2 Studio software was used, which is able to generate data that identify, for each individual, the sequence of eye movement, the points of the images that were most observed and the observation time of areas selected in the images. The Stata13.0 software was used to verify the statistical significance of results. The original images are shown in Fig. 1 (parts of the images were blurred in order to be shown in this paper).

Although, in Fig. 1, all images have been put together, in the experiment images A, B, $\mathrm{C}$ and $\mathrm{D}$ were presented sequentially. This figure shows with an arrow the location of each warning message for the reader, but these arrows were not shown to the experiment subjects. In images $\mathrm{A}$ and $\mathrm{D}$, the words are: "Drink responsibly" and in image $\mathrm{B}$ and C: "Don't drink and drive".

After $28 \mathrm{~s}$ of exposure to images, the individual was asked to complete a brief questionnaire whose goal was to verify which information he had remembered referring to the stimuli. The study included 60 participants, 31 men and 29 women. According to Lemercier et al. (2014), previous pupillometry studies used varied numbers of participants (from 10 to 45, with an average of 24 and a median of 21 participants). Bojko and Adamczyk (2010) indicate that 30 participants can be considered sufficient for qualitative studies and for within-subjects ones with a large expected effect size, which is the 


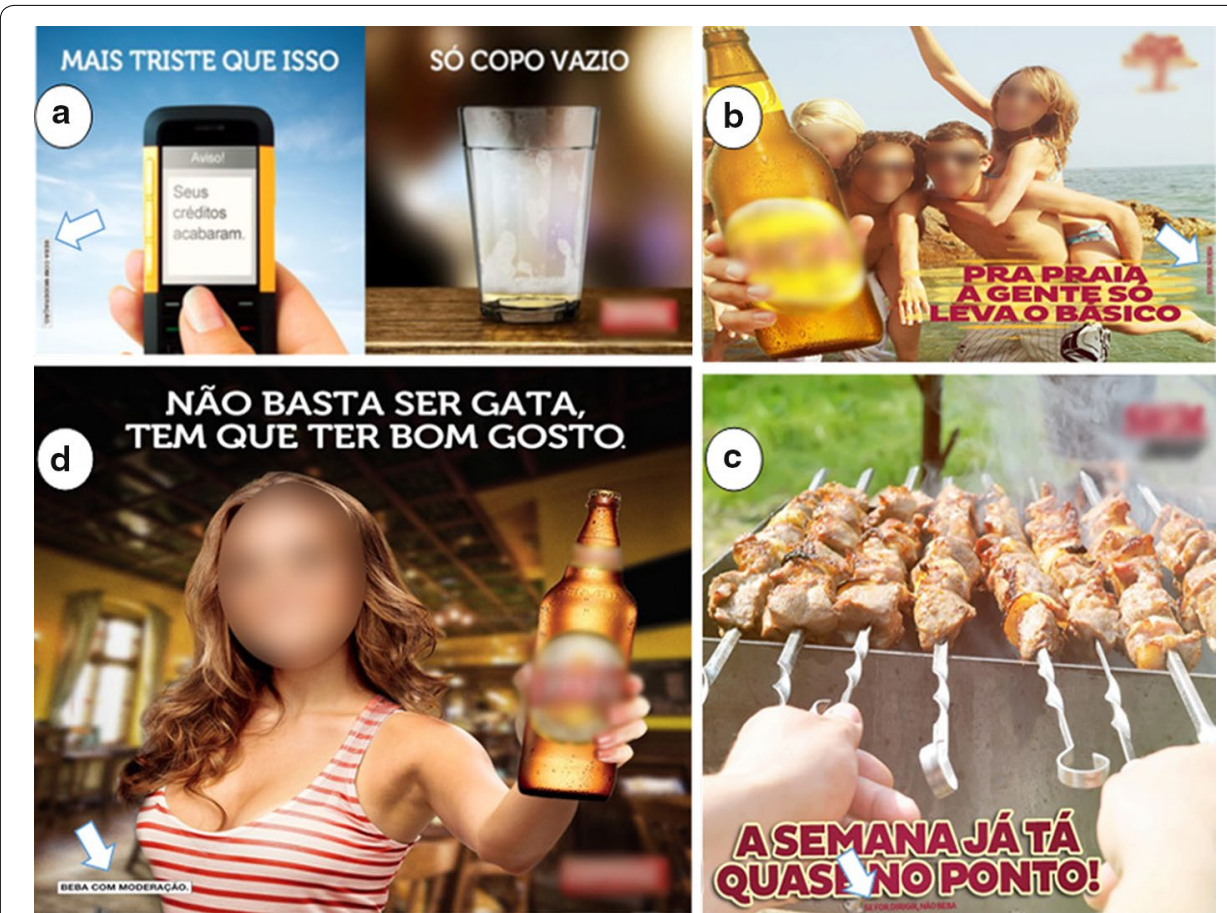

Fig. 1 Selected advertisements. Source companies'social networks

case of this research. Considering this, a sample of 60 participants seemed suitable in comparison to average sample sizes in eye-tracking studies.

\section{Results}

Figure 2 shows a heat map for each of the figures presented, identifying a general and cumulative view of the visual behavior of study participants. This visual representation of the attention on parts of images was made highlighting three color shades for the fixation levels: green, yellow and red. Green color represents few fixations, yellow color represents intermediate intensity of fixations and red color represents a high number of fixations of the visual attention of participants. That is, the heat map is the accumulated balance of observations in each point of the image, and point with no color means that there was no observation at that point.

As can be seen by results in Fig. 2, there were few views of warning visual stimuli in images $A$ and D, represented by green markings. However, images $B$ and $C$ virtually show no heat map markings for warning visual stimuli, indicating that there was very low view of these warnings. Of the four warnings, there were no yellow (intermediate intensity) or red markings (high intensity).

This research also sought to identify two variables related to visual attention behavior in order to complement the heat map information: the average duration of each fixation on AOIs and the total duration in all AOIs. The first variable calculates the average time that each individual retained attention every time they looked at an AOI of warning messages. Clearly enlightening the inefficiency of warning messages, at least in terms of reading and attention, the result showed a very low level of attention, with $0.3 \mathrm{~s}$ (Fig. 3). The same alarming numbers occur when summing all visual attention to AOIs, i.e., the 

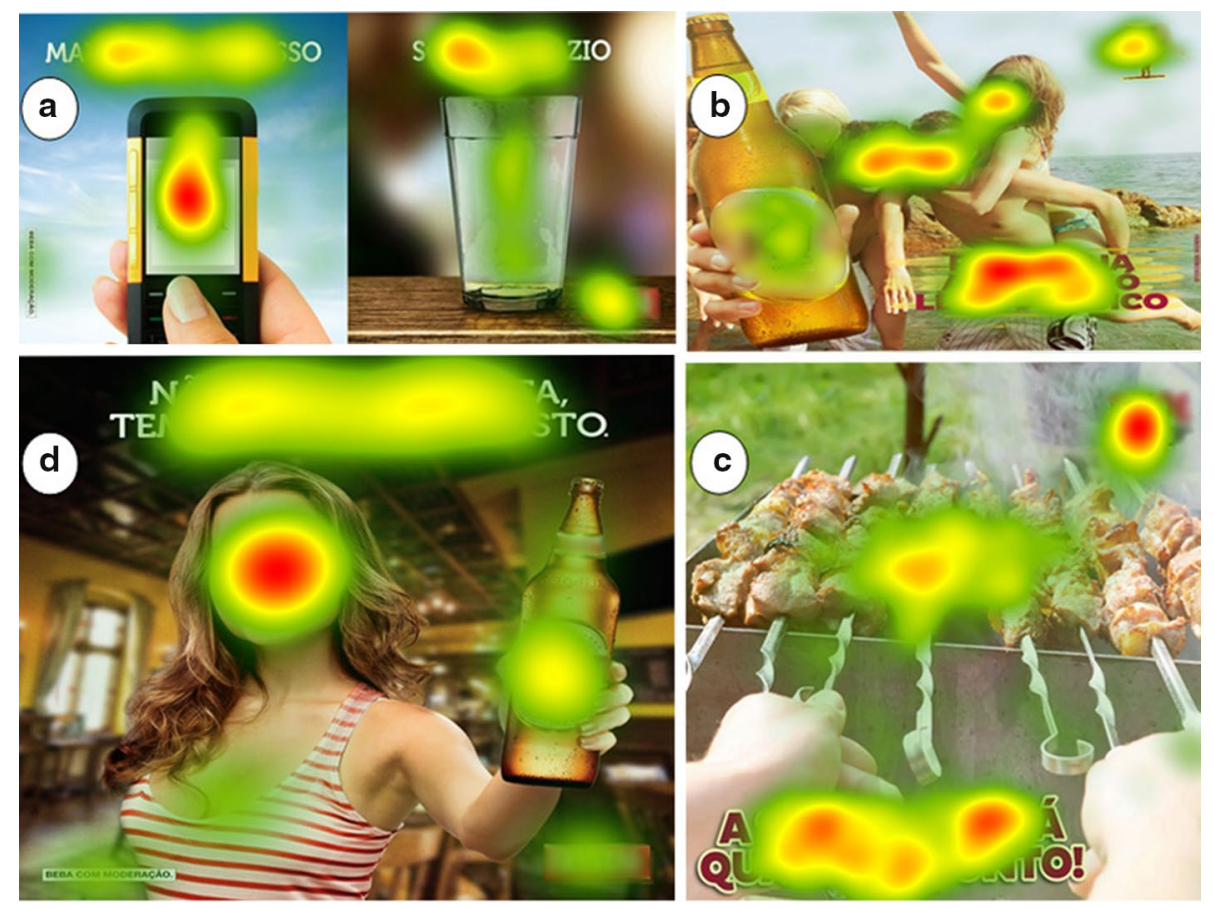

Fig. 2 Viewing heat map. Source research data

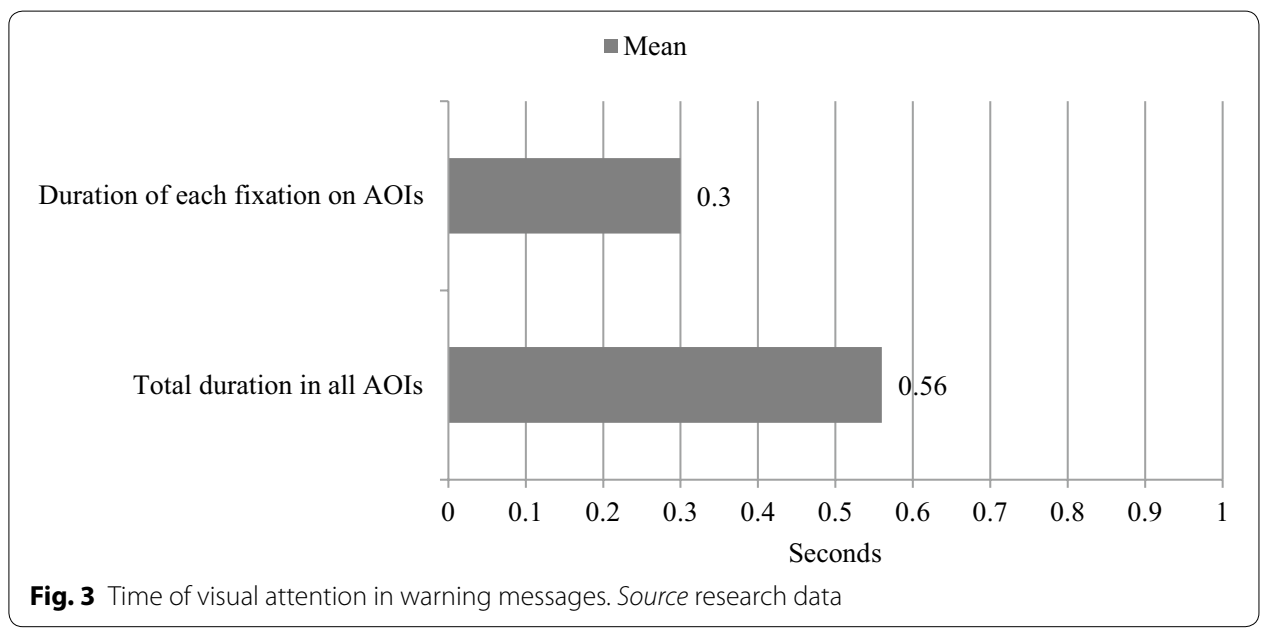

sum of the total average duration time: $0.56 \mathrm{~s}$. Taking into account that the total stimulation time was $28 \mathrm{~s}$, the total time spent on warning messages was only $2.0 \%$.

Although the result of only $2.0 \%$ of visual attention in warning messages is alarming, it is still possible to imagine that it resulted in reading. To complement this analysis, the study sought to identify the level of memory and awareness on warning messages through a semi-structured questionnaire. Respondents were asked to write all messages and information they remember concerning the stimuli newly viewed.

The questionnaire was administered immediately after the experiment aiming to use the short-term memory of respondents, although it is not possible to separate it from a previous memory in accumulated warning messages viewed by individuals. 
Nevertheless, it is reasonable to consider that the results obtained this way are weakened over time, that is, the awareness efficiency will be lower over hours and days in relation to the initial viewing, further reducing the proposal of consumer awareness.

Of the 60 participants, 34 (56\%), indicated that they viewed the warning messages. These views, as shown in Fig. 3, were of very poor quality of visual attention. Of these 34 participants, only two reported remembering warning messages about conscious consumption of alcoholic beverages, that is, only $3.33 \%$ of total participants.

Such result was expected. As it can be seen in the advertisements analyzed, all warning messages are located in peripheral areas of the images, occupying an insignificant area. Moreover, there are no visual effects that attract the view. All these facts contribute to not generating stimulus enough to call consumers' attention, as statistically evidenced in this paper. The tests proved that the larger the area occupied by the warning messages, more the consumers are likely to view them. Therefore, in order to improve the effectiveness of such messages, it is necessary to stipulate a minimum size they should occupy in advertisements.

The level of warning messages' attractiveness should be very well thought out, studied and tested by advertisement agencies when releasing campaigns that promote the consumption of alcohol. They should be linked to the issue of encouraging moderate, conscious and sustainable consumption of such product.

\section{Conclusions}

The evidence obtained in the results of this research point to alarming data for the formulation of public health policies with regard to excessive alcohol consumption. Apparently, warning messages are not efficient and it could be inferred that the process of transmitting messages is not attractive to consumer perception. Additionally, the objectives of warning messages are not achieved because the consumer awareness level is very low, that is, consumers have difficulty in viewing messages and when they view them, they are not aware of them.

Being aware of the warning message simply means that consumers remember the existence of it. This initial step is vital for behavior change, i.e., awareness of the potential harms of excessive alcohol consumption. Certainly, visual attention and the awareness of the warning existence do not guarantee that an individual, after reading the warnings of advertisements, will stop drinking alcohol if he or she is going to drive, or will not abuse alcohol. However, it is believed that the likelihood of this type of behavior change increases when the consumer actually realizes the existence of warning messages.

Based on the results of this research, further studies should be focused on consumer awareness level on the same theme, exploring the issue of how the consumer can be aware of the various problems of excessive alcohol consumption or driving under influence (DUI) and investigate how consumers can become aware of these problems by these warning messages.

Given the importance of this issue to public health, this study aimed to highlight the importance of understanding the consumer behavior for the effective implementation of public policies, in order to actually generate positive results. Finally, this research also sought to highlight the potential of neuromarketing research, in which through different 
tools, behavioral characteristics and patterns can be verified and assessed. The use of this tool for public health is a major source of potential resources in this attempt.

As a final remark, based on the results of the article, some guidelines can be proposed to the Government, in order to make the warning messages more effective (such as stipulating a minimum size they should occupy in advertisements, as previously mentioned). However, it is not believed that the consumer will be aware just by reading consumption prevention messages in advertisements; this is just an instrument of the many that exist. The government and industries should create prevention campaigns to alcohol consumption. Another suggestion would be the government offer tax incentives for organizations that conduct campaigns to encourage the moderate, conscious and sustainable consumption of alcoholic beverages. Thus, the organizations could compensate the decrease in sales with lower taxes.

\section{Authors' contributions}

$J \mathrm{HCO}$ and ROJS designed and collected the research data. JHCO and ROJS analyzed the data and drafted the manuscript. JMEG and ARBT participated in the critical revision, providing important improvements concerning the data interpretation and final presentation. All authors discussed the results and implications and commented on the manuscript at all stages. All authors read and approved the final manuscript.

\section{Author details}

${ }^{1}$ University of São Paulo (USP), Av. Bandeirantes 3900, Monte Alegre, Ribeirão Prêto, SP CEP 14040-905, Brazil. ${ }^{2}$ University of São Paulo (USP), Av. Duque de Caxias Norte, 225, Pirassununga, SP CEP 13635-900, Brazil.

\section{Compliance with ethical guidelines}

Competing interests

The authors declare that they have no competing interests.

Received: 22 June 2015 Accepted: 24 August 2015

Published online: 04 September 2015

\section{References}

Albuquerque MFPMF, Ximenes RAA, Lucena-Silva N, Souza WV, Dantas AT, Dantas OMS, Rodrigues LC (2007) Factors associated with treatment failure dropout, and death in a cohort of tuberculosis patients in Recife, Pernambuco State, Brazil. Cad Saúde Pública 23:1573-1582

Almeida JF, Carvalho KD, Crus STM, Carvalho MFAA, Figueiredo RGT (2013) Alcohol use among of public school students. J Nurs UFPE On Line 7:397-406

Boffetta P, Hashibe M (2006) Alcohol and cancer. Lancet Oncol 7:149-156

Bojko A, Adamczyk KA (2010) More than just eye candy: top ten misconceptions about eyetracking. User Exp 9:4-8

Buscher G, Dumais ST, Cutrell E (2010) The good, the bad, and the random: an eye-tracking study of ad quality in web search. In: Proceedings of the international ACM SIGIR conference on research and development in information retrieval, vol 33, pp 42-49

Caswell S (2004) Alcohol brands in young people's everyday lives: new developments in marketing. Alcohol Alcohol 39:471-476

Caswell S, Maxwell A (2005) Regulation of alcohol marketing: a global view. J Public Health Policy 26:343-358

D'Andrea G, Ventura CAA, Costa Júnior ML (2013) Social use of alcohol among adolescent offenders: a fundamental approach toward human needs. Rev Esc Enferm USP 48:133-140

Duailibi S, Laranjeira R (2007) Políticas públicas relacionadas às bebidas alcoólicas. Rev Saúde Pública 41:839-848

Eloah MI, Lana FCF, Felisbino-Mendes MS, Malta DC (2013) Factors associated with alcohol intake and alcohol abuse among women in Belo Horizonte, Minas Gerais State, Brazil. Cad Saúde Pública 29:1449-1459

Falcão ISL, Rangel-S ML (2010) Controle sanitário da propaganda de bebidas alcóolicas no Brasil: Estudo dos projetos de lei de 1988 a 2004. Ciênc Saúde Colet 15:3433-3442

Ferreira LN, Sales ZN, Casotti CA, Bispo Júnior JP, Braga Júnior ACR (2011) Perfil do consumo de bebidas alcoólicas e fatores associados em um município do Nordeste do Brasil. Cad Saúde Pública 27:1473-1486

Fiszman BP, Velasco C, Salgado-Montejo A, Spence C (2013) Using combined eye tracking and word association in order to assess novel packaging solutions: a case study involving jam jars. Food Qual Prefer 28:328-338

Fugate DL (2007) Neuromarketing: a layman's look at neuroscience and its potential application to marketing practice. J Consum Mark 24:385-394

Lemercier A, Guillot G, Courcoux P, Garrel C, Baccino T, Schlich P (2014) Pupillometry of taste: methodological guide from acquisition to data processing - and toolbox for MATLAB. Quant Methods Psychol 10:179-199

Malta DC, Berna RTI, Silva MMA, Claro RM, Silva Júnior JB, Reis AAC (2014) Consumo de bebidas alcoólicas e direção de veículos, balanço da lei seca, Brasil 2007 a 2013. Rev Saúde Pública 48:692-696 
Ministério da Saúde (2010) "Lei Seca" reduz em 6,2\% as mortes causadas pelo trânsito. Portal da Saúde. Recuperado em 12 maio, 2012 de http://portal.saude.gov.br/portal/aplicacoes/noticias/default. $\mathrm{cfm} ? \mathrm{pg}=\mathrm{dspDetalheNoticia \& id \_ area}=1450 \& C O \_N O T / C \mid A=11454$

Montagu JD, Coles EM (1966) Mechanism and measurement of the galvanic skin response. Psychol Bull 65:261-279

Nielsen J, Pernice K (2009) Eyetracking web usability. New Riders, Berkeley

Oliveira JHC, Giraldi JME, Santos ROJ (2014) Opening the -black box-in the consumer's mind: understanding what is neuromarketing. Int J Bus Manag 9:96-107

Pöschl G, Seitz HK (2004) Alcohol and cancer. Alcohol Alcohol 39:155-165

Rosa SES, Consenza JP, Leão LTS (2006) Panorama do setor de bebidas no Brasil. BNDES Setorial 23:101-149

Tobii (2014) Product descriptions. http://www.tobii.com/en/eye-tracking-research/global/library/product-descriptions. Retrieved Nov 172014

Velásquez JD (2013) Combining eye-tracking technologies with web usage mining for identifying website keyobjects. J Eng Appl Artif Intell 26:1469-1478

Visser RO, Wheeler Z, Abraham C, Smith JA (2013) Drinking is our modern way of bonding: young people's beliefs about interventions to encourage moderate drinking. Psychol Health 28:1460-1480

Weigle C, Banks DC (2008) Analysis of eye-tracking experiments performed on a Tobii T60. University of Tennessee/Oak Ridge National Lab/Joint Institute for Computational Sciences, Oak Ridge

\section{Submit your manuscript to a SpringerOpen ${ }^{\circ}$ journal and benefit from:}

- Convenient online submission

- Rigorous peer review

- Immediate publication on acceptance

- Open access: articles freely available online

- High visibility within the field

- Retaining the copyright to your article

Submit your next manuscript at $\boldsymbol{\nabla}$ springeropen.com 